\title{
Effectiveness of anonymised information sharing and use in health service, police, and local government partnership for preventing violence related injury: experimental study and time series analysis
}

\author{
Curtis Florence, senior health economist, ${ }^{1}$ Jonathan Shepherd, professor of oral and maxillofacial surgery and \\ research group director, ${ }^{2}$ Iain Brennan, lecturer, ${ }^{3}$ Thomas Simon, associate director for science ${ }^{1}$
}

\begin{abstract}
${ }^{1}$ Division of Violence Prevention, Centres for Disease Control and Prevention, Atlanta, GA, USA 2Violence and Society Research Group, School of Dentistry, Cardiff University, Cardiff CF14 4XY, UK

${ }^{3}$ Department of Social Sciences, University of Hull, Hull

Correspondence to: J P Shepherd shepherdjp@cardiff.ac.uk

Cite this as: $B M J$ 2011;342:d3313 doi:10.1136/bmj.d3313
\end{abstract}

\section{ABSTRACT}

Objective To evaluate the effectiveness of anonymised information sharing to prevent injury related to violence. Design Experimental study and time series analysis of a prototype community partnership between the health service, police, and local government partners designed to prevent violence.

Setting Cardiff, Wales, and 14 comparison cities designated "most similar" by the Home Office in England and Wales.

Intervention After a 33 month development period, anonymised data relevant to violence prevention (precise violence location, time, days, and weapons) from patients attending emergency departments in Cardiff and reporting injury from violence were shared over 51 months with police and local authority partners and used to target resources for violence prevention.

Main outcome measures Health service records of hospital admissions related to violence and police records of woundings and less serious assaults in Cardiff and other cities after adjustment for potential confounders.

Results Information sharing and use were associated with a substantial and significant reduction in hospital admissions related to violence. In the intervention city (Cardiff) rates fell from seven to five a month per 100000 population compared with an increase from five to eight in comparison cities (adjusted incidence rate ratio 0.58 , $95 \%$ confidence interval 0.49 to 0.69 ). Average rate of woundings recorded by the police changed from 54 to 82 a month per 100000 population in Cardiff compared with an increase from 54 to 114 in comparison cities (adjusted incidence rate ratio $0.68,0.61$ to 0.75 ). There was a significant increase in less serious assaults recorded by the police, from 15 to 20 a month per 100000 population in Cardiff compared with a decrease from 42 to 33 in comparison cities (adjusted incidence rate ratio 1.38, 1.13 to 1.70$)$.

Conclusion An information sharing partnership between health services, police, and local government in Cardiff, Wales, altered policing and other strategies to prevent violence based on information collected from patients treated in emergency departments after injury sustained in violence. This intervention led to a significant reduction in violent injury and was associated with an increase in police recording of minor assaults in Cardiff compared with similar cities in England and Wales where this intervention was not implemented.

\section{INTRODUCTION}

According to the World Health Organization, in 2004 interpersonal violence resulted in over 600000 deaths and around 17.2 million serious injuries throughout the world. ${ }^{1}$ In 2002, interpersonal violence (excluding operations of war and self inflicted injury) was the fifth most common cause of death worldwide among people aged 15-29 and sixth most common among those aged 30-44. Consequently, WHO has identified interpersonal violence as a global public health issue. In 2008-9, police recorded over 900000 violent incidents in England and Wales, representing 1643 violent incidents per 100000 population; the murder rate was 1.1 per 100000 population. ${ }^{2}$ In the United Kingdom, interpersonal violence in 2003-4 resulted in medical and lost productivity costs of $£ 2.1 \mathrm{bn}(€ 2.3 \mathrm{bn}$; $\$ 3.3 \mathrm{bn})$ and $£ 1.7 \mathrm{bn}$, respectively. ${ }^{3}$

Efforts at preventing violence can be implemented at individual, relationship, and community levels. As cultures of violence are often developed and reinforced at the community level, ${ }^{4}$ prevention strategies implemented at this level can reach large groups of individuals at risk. There are, however, few scientific evaluations of violence prevention programmes at the community level. ${ }^{5}$

We evaluated a novel community violence prevention programme developed over three years and fully implemented in 2001 in Cardiff, Wales (population 324800 in 2001). The theoretical basis of this programme is that by enhancing information available from the police with relevant data from emergency departments and by including health professionals responsible for treating the injured as advocates for prevention, more violence can be prevented than from police effort alone. 
Beginning in the UK, ${ }^{67}$ and subsequently in Scandinavia, ${ }^{8}$ studies matching data from emergency departments and police have shown that only a quarter to one third of violent incidents that result in treatment in an emergency department appear in police records. These estimates are consistent with the findings of large scale national crime surveys. ${ }^{2}$ Even the most serious violence might not be known to the police. In the United States, for example, 13\% of shootings resulting in emergency department care in Atlanta, GA, were not included in city-wide police records. ${ }^{9}$ Reasons for low police ascertainment include reliance on victims to report offences, fear of reprisals, not knowing the identity of assailants, few incentives to report, and unwillingness of victims to have their conduct scrutinised. ${ }^{210}$ Findings in the UK to this effect persuaded the government to adopt a multi-agency approach to violence prevention, which includes the health sector. Building on the prototype partnership described below, the UK 1998 Crime and Disorder Act placed a legal obligation on police, local government, and the National Health Service (NHS) to collaborate to develop and implement joint crime reduction strategies. This legislation led to the formation of more than 350 local statutory partnerships by 2000 .

Although laws in some countries and US states mandate the reporting by medical staff of some violent offences that result in treatment, knowledge of these is generally low and, for various reasons, many physicians choose not to report. In one study, the introduction of mandatory reporting of domestic violence did not increase reporting. ${ }^{11}$ Moreover, the motivation for such legislation has been improvement of services for victims and increasing detection of offenders rather than to inform and drive violence prevention at the community level. ${ }^{12}$ International comparisons have shown that only a proportion of all violent offences are reported to the police and that only a proportion that are reported result in police recording. For example, in a comparison of violence affecting adults (aged over 16) in 1999 in eight Western countries, reporting rates varied from $24 \%$ in the Netherlands to $52 \%$ in the US and recording rates for those reported varied from $20 \%$ in Switzerland to $82 \%$ in the US. ${ }^{13}$

Violence prevention efforts can be enhanced by collaboration between public health and the police. For example, epidemiological data on the time, circumstances, and location of homicides in Cali, Colombia, have been used to inform allocation of police resources and state and city regulations, resulting in a $30 \%$ decrease in homicide, representing about 600 fewer violent deaths between 1994 and 1997. ${ }^{14}$ In South Africa, a collaboration between public health orientated research groups led to the establishment of a nationwide violence and injury surveillance system that has been used to inform police crime information systems. ${ }^{15}$ In the US, the National Violent Death Reporting System links health and law enforcement data. ${ }^{16}$ There is also convincing evidence from randomised experiments ${ }^{1718}$ and in a systematic review for the Campbell Collaboration that targeted policing can be effective in reducing crime and disorder. ${ }^{19}$ Evaluations have concluded that violence and other categories of crime, most of which is spontaneous, are rarely displaced by police activity; rather, prevention effects of targeted policing often extend to areas immediately surrounding the location targeted. ${ }^{20}$ The locations of concentrations of violence ("hot spots"), however, change, sometimes rapidly-for example, in urban night time economies where the number and locations of premises licensed to sell alcohol vary over time-which implies that continuous access to and use of reliable data are important.

We examined the effectiveness of a health led, multiagency violence prevention partnership. It was hypothesised from the start that a partnership between health and police practitioners and city government officials working together and using data collected in emergency departments as well as police intelligence to inform targeted policing and other strategies, would prevent violence to a greater extent than city partnerships in which emergency departments data are not collected and used. This hypothesis was the reason both for setting up the prototype partnership and the process for data collection and use. ${ }^{21}$

\section{METHODS}

Cardiff Violence Prevention Programme (CVPP)—a data sharing strategy for violence prevention

In July 1997, a prototype partnership - a multi-agency violence prevention group made up of representatives of the city government, police, city licensing regulators, and an emergency department consultant and chaired by a professor of oral and maxillofacial surgery-was convened to implement this approach in Cardiff. In time, membership expanded to include representatives of education, transport and ambulance services, and local licensees. After careful refinement in a research and development initiative (the Tackling Alcohol-related Street Crime project, 1999-2002, http://kb.keepbritaintidy.org/nighttime/casestudies/ cardiff.pdf) funded by the Home Office, particularly of arrangements to anonymise, share, summarise, and use data derived from the emergency department, ${ }^{22}$ the full violence prevention programme became operational in January 2003. At this point, full data sharing and use were implemented and the prototype partnership was formally adopted by the city government and its police and health service partners.

Processes for data capture, sharing, and use have already been published. ${ }^{2223}$ In summary, for all patients reporting injury in a violent incident, information about the precise location of the incident (name of bar, nightclub, school, park, street, etc), time and day, and type of weapon is captured electronically ${ }^{24}$ in the emergency departments by reception staff when patients first attend, stripped of personal identifiers, and shared by hospital IT staff on a monthly basis with the partnership crime analyst. The analyst then combines data with police intelligence to generate constantly updated maps of violence "hotspots" and summaries of weapon use and violence type (classified as 
"stranger," "acquaintance," and "domestic" to fit with national crime survey categorisation). Integrated violence prevention is then based on this combined, continuously updated information.

Uniquely in Cardiff and throughout this study, data derived from the emergency departments relevant to targeted violence prevention were combined with police data and used to deploy prevention resources. This prototype partnership met about every six weeks and, based on the combined data, introduced and sustained a range of strategies designed to address specific risks and patterns observed in the data. These strategies comprised repeated adjustments to the routes of police patrols and moving police resources from the suburbs to the city centre at weekends to ensure that police were present and able to intervene at specific locations and times identified by the data, targeting problematic licensed premises (by police and city government officials responsible for alcohol licensing) and informing public space deployment of closed circuit television

\section{Box 1: Standard definitions of assault types}

More serious wounding: Injury resulting in permanent disability or permanent loss of sensory function; injury that results in more than minor permanent, visible disfigurement; broken or displaced limbs or bones (including fractured skull); compound fractures, broken cheek bone, jaw or ribs, etc; injuries that cause substantial loss of blood, usually necessitating a blood transfusion; injuries resulting in lengthy treatment or incapacity

Less serious wounding: Loss or breaking of tooth or teeth; temporary loss of sensory functions (including loss of consciousness); extensive or multiple bruising; displaced broken nose; minor fractures; minor but not merely superficial cuts

Common assault: Grazes; scratches; abrasions; minor bruising; swellings; reddening of the skin; superficial cuts; a "black eye" as well as ... assault resulting in no injury

Box 2: Sociodemographic and geographical variables used to cluster most similar cities

Percentage of young men (aged 16-24)

Percentage of minority ethnic population

Percentage of single adult households

Percentage of single parent households

Percentage of student households

Percentage of residents living at a different address one year before the 1991 census

Percentage of local authority housing, plus new town renters and housing associations

Percentage of terraced housing

Percentage of overcrowding

Population sparsity

Population density

Length of $A, B$, and minor roads per head of population

Motorway junctions per 1000 population

Percentage of daytime population

Percentage of young male claimants of unemployment related benefits

Percentage of long term claimants of unemployment related benefits

Index of overcrowding homogeneity

Population per square kilometre

Percentage of claiming income support

Percentage of claiming family credit
(CCTV). ${ }^{23}$ Over the course of the intervention period, the partnership (which became the statutory UK approach to crime prevention after the Crime and Disorder Act) initiated and coordinated violence prevention initiatives. Prevention strategies unrelated to targeted policing were also implemented by the city government, prompted by the combined data and other factors such as the need to improve traffic flow and public transport arrangements. These included pedestrianising sections of a city centre street where bars and nightclubs are mainly concentrated (February 2004), mandatory use of plastic glassware in selected licensed premises (after 2005), and more frequent late night public transport services (from February 2004). The unique characteristics of the partnership that were not present in any other UK city partnership during the period of the evaluation were the systematic collection, summary, and use of emergency department data for violence prevention and the participation of emergency department and maxillofacial clinicians in statutory partnership meetings. The common attitudes of trauma specialists and police managers - both responsive, action oriented practitioners - were evident in the mature partnership.

There were no other major changes in law enforcement or emergency or trauma services in the intervention city during the study period, throughout which the city was served by the same single emergency department.

\section{Study design}

We used an experimental research design to compare changes in violence in Cardiff, the intervention city, with changes in violence in the comparison sites-14 cities classified by the Home Office as "most similar." Changes were analysed with consistent monthly data, starting in April 2000 with the appointment of a data analyst and continuing to March 2007, when the Home Office revised its "most similar" city categories. There were 33 months of observation before the Cardiff programme was implemented and 51 months after implementation. Outcome measures in this study were violence recorded by the police (subcategorised as wounding, common assault, and total assault according to standard definitions, box 1$)^{25}$ and hospital admissions related to violence, a health services measure of community violence. ${ }^{26}$

With regard to police records, Cardiff was compared with 14 "most similar" cities identified by the UK Home Office (the lead government department for police): Birmingham, Bristol, Coventry, Derby, Leeds, Leicester, Lincoln, Newcastle upon Tyne, Northampton, Plymouth, Preston, Reading, Sheffield, and Stoke on Trent. Cities were clustered (k-means) according to an array of 20 sociodemographic and geographic factors, which, together, are linked to levels of crime (box 2). ${ }^{27}$

Groups of these most similar cities are used by the UK government as the basis of managing performance of police forces and statutory partnerships. As these cities are clustered according to many variables, they 
Table 1| Unadjusted monthly average counts and population adjusted monthly rates of hospital admissions after violence, police recorded woundings, and police recorded common assaults in Cardiff and comparison cities before and after implementation of Cardiff Violence Prevention Programme

\begin{tabular}{|c|c|c|c|c|c|c|}
\hline & \multicolumn{2}{|c|}{ Admissions after violence } & \multicolumn{2}{|c|}{$\begin{array}{l}\text { Police recorded wounding } \\
\text { assaults }\end{array}$} & \multicolumn{2}{|c|}{$\begin{array}{c}\text { Police recorded common } \\
\text { assaults }\end{array}$} \\
\hline & Cardiff hospital & Comparison cities & Cardiff & Comparison cities & Cardiff & Comparison cities \\
\hline \multicolumn{7}{|c|}{ Unadjusted count (monthly average) } \\
\hline Before implementation & 21.03 & 21.20 & 168.52 & 181.03 & 47.79 & 142.65 \\
\hline After implementation & 16.89 & 33.35 & 256.76 & 382.48 & 61.14 & 110.88 \\
\hline \multicolumn{7}{|c|}{ Population adjusted rate of violence (per 100000 population) } \\
\hline Before implementation & 6.71 & 5.33 & 53.79 & 53.86 & 15.25 & 42.44 \\
\hline After implementation & 5.39 & 8.39 & 81.96 & 113.80 & 19.51 & 32.99 \\
\hline
\end{tabular}

constitute an appropriate comparison group for our study. In addition, hospital admission data were available in Cardiff and in three of the 14 most similar cities (Leeds, Reading, and Sheffield). Attendance data for emergency departments were also available from Cardiff but not in sufficient quality from comparison cities for this measure to be included. Because strength of the police force ${ }^{28}$ and city unemployment rates ${ }^{29}$ have been found to be linked with incidence and recording of violence, we controlled for both in the model. The data on unemployment rate reflect the monthly percentage of eligible workers aged 16-64 who claimed unemployment benefits. Police force strength was characterised as the annual number of officers per 100000 population..$^{30-37}$

\section{National crime recording standard (NCRS)}

The national crime recording standard, designed to standardise (previously highly inconsistent) crime recording by the police was introduced, police force by police force, across England and Wales between 1999 and 2002, increasing recording rates. This standard was introduced in the South Wales police force area (of which Cardiff is a major urban constituent) in April 2002, resulting in a 25-33\% increase in rates of recorded violence. ${ }^{38}$ We controlled for implementation of the standard in the analysis as described below.

\section{Statistical analyses}

Time trends in crude assault rates

To compare changes in rates of violence over time, we compared Cardiff rates, by month, with the mean rates

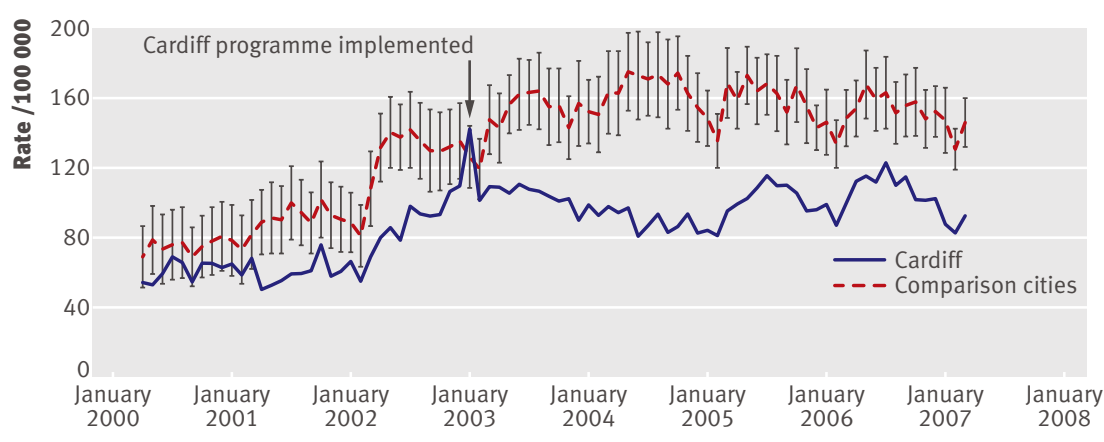

Fig 1 Total assault rates by month for Cardiff and mean of comparison cities with $95 \%$ confidence intervals of the comparison cities. We compared the actua assault rate for Cardiff with the 95\% confidence interval of the mean in the comparison cities to determine if the Cardiff rate was statistically different from that mean. The comparison is made for total, common, and wounding assaults.

\section{Multivariable regression modelling}

To control for the effect of the national crime recording standard and other potential covariates, we estimated negative binomial regression models with counts of a given type of violence recorded in each city in each month as the dependent variable. The negative binomial model is similar to a Poisson regression model but does not impose the Poisson assumption that the mean and variance of the dependent variable are equal. Likelihood ratio tests conducted on the models indicated that the negative binomial model fits the data better than the Poisson model in each regression presented. The population of each city is included as a control variable to account for the different population sizes and to allow for the interpretation of regression coefficients as incidence rate ratios. As each city is observed repeatedly over time, it is also possible to control for differences across cities that do not vary over time. Conditional fixed effects negative binomial regression was estimated in Stata version 10 to control for these time invariant factors. Separate models were calculated with all woundings, common assaults, total assaults (all woundings and common assaults), and hospital admissions for violence as dependent variables.

The main independent variable in the models is a dummy variable equal to 1 for all months and cities where the Cardiff programme was in place (in this case, solely Cardiff) and equal to 0 for all other places. This variable allows us to test the association between violence and the presence of the Cardiff programme. The model can also provide an estimate of the change in violence that occurred in Cardiff after the programme was implemented, while controlling for the change in violence in the comparison cities. The coefficient on this variable reflects the difference in rates of violence in Cardiff after the programme was implemented net of any changes in rates of violence in the control cities after implementation of the programme.

To control for the overall increase in recording of violence because of the national crime recording 
Table 2 Outcomes and independent variables for Cardiff, comparison cities, and all cities in study of implementation of Cardiff Violence Prevention Programme. Figures are means (SE) (over time of study)

\begin{tabular}{lccc} 
& $\begin{array}{c}\text { Cardiff } \\
(\mathrm{n}=84)\end{array}$ & $\begin{array}{c}\text { Comparison cities* } \\
(\mathrm{n}=1140)\end{array}$ & $\begin{array}{c}\text { All cities } \\
(\mathrm{n}=\mathbf{1 2 2 4})\end{array}$ \\
$\begin{array}{l}\text { Monthly average recorded by police: } \\
\text { Total assaults }\end{array}$ & $278(7)$ & $433(9)$ & $422(9)$ \\
\hline Common assaults & $56(2)$ & $123(3)$ & $118(3)$ \\
\hline Wounding assaults & $222(6)$ & $310(8)$ & $304(8)$ \\
\hline Rate/100 000 population recorded by police: & $89(2)$ & $135(1)$ & $32(1)$ \\
\hline Total assaults & $18(0.5)$ & $41(1)$ & $92(1)$ \\
\hline Common assaults & $71(2)$ & $94(1)$ & $335(6)$ \\
\hline Woundings & $313(1)$ & $336(7)$ & $3(0.03)$ \\
\hline Population (thousands) & $3(0.03)$ & $3(0.03)$ & $422(2)$ \\
\hline Unemployment rate & $471(2)$ & $419(2)$ & \\
\hline No of police/100 000 population & & & \\
\hline
\end{tabular}

*Birmingham, Bristol, Coventry, Derby, Leeds, Leicester, Lincoln, Newcastle upon Tyne, Northampton, Plymouth, Preston, Reading, Sheffield, Stoke on Trent.

standard, we introduced a dummy variable coded as 0 for months before implementation and 1 for months after. Changes in overall violence trends that could be common across all the cities in the sample were controlled for by including dummy variables for the calendar year of a given observation. Each model also controlled for unemployment rates and police force strength. To test if the impact of the intervention changed over time, we calculated an identical set of models with the addition of the Cardiff programme by year dummy variable interaction terms.

We also performed a parallel set of analyses of hospital admissions for violence from Cardiff and the three "most similar" cities for which monthly admissions data were available (January 2000 to December 2005). Seventy two months of data (36 before and 36 after implementation of the Cardiff programme) were available for this outcome.

\section{RESULTS}

Table 1 shows the unadjusted monthly average counts and population adjusted monthly rates of hospital admissions and violence recorded by the police after violence.

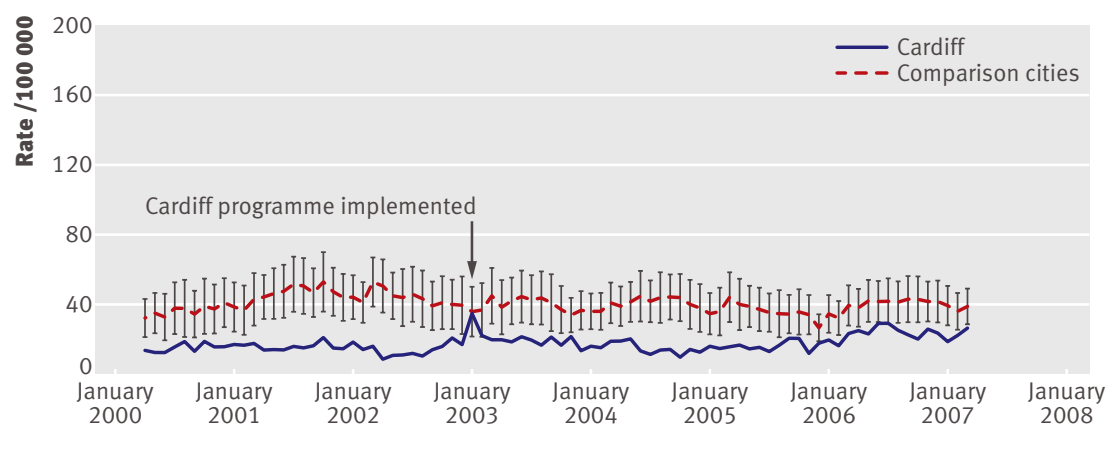

Fig 2 | Common assault rates by month for Cardiff and mean of comparison cities with $95 \%$ confidence intervals
Time trends in crude assault rates

For total assaults (fig 1), Cardiff was generally below the mean of the comparison cities in the period before the programme, but this difference is often within the confidence interval, especially in the year 2000 and in the months just before implementation. Both Cardiff and the comparison cities also showed an upward trend in total assaults before implementation - reflecting adoption of the national crime recording standard. After implementation, however, there is a clear divergence in the two series. Total assaults began to decline in Cardiff, while they continued to increase in the comparison cities. Cardiff's total assault rate was also consistently outside the confidence interval of the comparison cities after the programme was implemented.

Figure 2 shows the trends for common assault rates. For this measure, Cardiff was consistently below the mean of the comparison cities, though there was some overlap in 2003 when the programme was implemented. There was some slight convergence of Cardiff with the other cities in 2006 and 2007, but Cardiff rarely fell within the confidence interval.

Figure 3 shows the trends for assaults causing wounding. For this more serious violence, Cardiff rarely fell outside the confidence interval of the comparison cities in the period before the programme. After the programme was implemented, however, Cardiff's rate began to decline and was consistently and significantly lower than the mean rate for the comparison cities over the remainder of the time series.

Taken together, these time series graphs suggest that there was a substantial reduction in risk for violence in Cardiff relative to other cities after the programme was implemented and that this was because of lower rates of violence causing wounding rather than less serious violence. It is still not clear if this difference can be attributed to the Cardiff programme or if the observed relation is caused by other confounding factors.

\section{Multivariable regression results}

Table 2 shows descriptive statistics for violence recorded by the police and all variables included in the regression estimation. Over the 84 months of the study, Cardiff had lower rates of total assaults and common assaults but similar levels of assaults causing wounding compared with the other cities. The mean population of Cardiff is slightly higher than 300000 and the mean population of comparison cities is similar (though there is considerable variation across comparison cities). Cardiff had slightly lower unemployment and somewhat greater police officer numbers per population over the study period.

Table 3 provides initial regression results for violence recorded by the police. Results are presented in terms of adjusted incidence rate ratios, which are the exponentiated coefficients from the negative binomial models. The rate ratio for implementation of the Cardiff programme shows that the average rate of total assaults after implementation of the programme was about $79 \%$ of the assault rate before implementation. This reduction is accounted for by a reduction in 


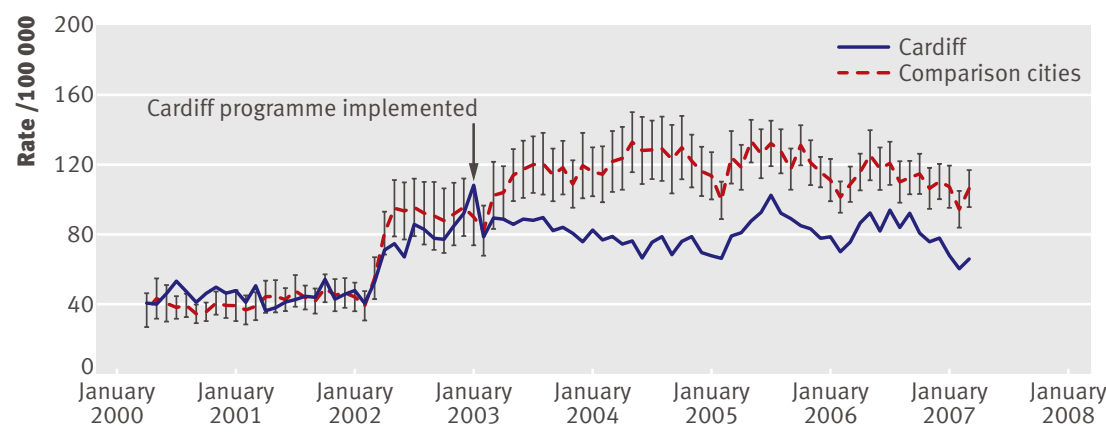

Fig 3 Wounding assault rates by month, Cardiff and mean of comparison cities. The national crime recording standard was implemented in Birmingham and Coventry in January 1999, in Stoke on Trent in October 1999, in Preston in August 2000, in Bristol in October 2000, in Leeds and Lincoln in February 2002, and in Cardiff, Derby, Leicester, Newcastle upon Tyne, Northampton, Plymouth, Reading, and Sheffield in April 2002

wounding assaults, which were $68 \%$ of the wounding assault rate before implementation. There was a $38 \%$ increase in the common assault rate associated with implementation. All of these rate ratios are significant at $\mathrm{P}<0.05$.

While these results show a strong association between the implementation of the Cardiff programme and a reduction in assaults, they assume that the effect of the programme is constant over the implementation period. Table 4 shows the results for specific years as well as the results of regression specification that allows the intervention effect to vary by interacting the intervention dummy with the year variables. We calculated incidence rate ratios by exponentiating the programme coefficient plus the programme*year coefficient. In 2003 (the reference year), the rate of total assaults was $93 \%$, and the rate of wounding assaults was $83 \%$ of the rates before the programme. The programme was associated with a large increase in common assaults recorded by the police in $2003(92 \%)$. After the first year of the Cardiff programme, however, there was a continued decline in all assaults and wounding assaults for 2004 and this level of assaults was maintained for subsequent years. For example, the programme was associated with a total assault rate of $71 \%$ and a wounding assault rate of $64 \%$ of the pre-programme rates in 2004. This level of decline was maintained through 2007. The increase in common assaults associated with programme dissipates after 2003. The incidence rate ratio is significantly smaller in 2004 and 2005 relative to 2003 and was not significant overall in 2004,2005, and 2007. Taken as a whole,

Table $3 \mid$ Adjusted $^{\star}$ incidence rate ratios (95\% confidence intervals) from negative binomial fixed effects regression models for total, common, and wounding assaults in Cardiff recorded by police after implementation of Cardiff Violence Prevention Programme

\begin{tabular}{llll} 
& \multicolumn{1}{c}{ Total assaults } & Common assaults & Wounding assaults \\
Programme implemented & $0.79(0.73$ to 0.85$)$ & $1.38(1.13$ to 1.70$)$ & $0.68(0.61$ to 0.75$)$ \\
\hline Unemployment rate & $0.89(0.86$ to 0.92$)$ & $0.88(0.81$ to 0.95$)$ & $0.89(0.85$ to 0.93$)$ \\
\hline Police $/ 100000$ population & $0.99(1.00$ to 1.00$)$ & $0.99(0.99$ to 0.99$)$ & $0.99(1.00$ to 1.00$)$ \\
\hline NCRS reporting system & $1.58(1.52$ to 1.65$)$ & $1.53(1.38$ to 1.70$)$ & 1.20 (1.14 to 1.28$)$ \\
\hline
\end{tabular}

NCRS=national crime recording standard.

*Regression also controls for calendar month and year (results not shown). these results suggest that the Cardiff programme was associated with a larger decrease in assaults after the first year of programme implementation.

Table 5 shows the descriptive statistics for hospital admissions. Both Cardiff and the comparison cities have similar admission rates for violence related injury. The comparison cities are slightly larger than Cardiff, and Cardiff has more police per population. The unemployment rates for Cardiff and comparison cities are also similar. The regression results (table 6) show that the programme was associated with a significant large reduction in the admission rate.

In Cardiff rates of hospital admissions fell from seven a month per 100000 population in the 36 months before implementation of the programme to five a month per 100000 population in the 36 months after implementation, but increased in comparison cities from five to eight a month per 100000 population. While rates of violence recorded by the police increased across all the study cities, the increase in Cardiff, from 54 a month per 100000 population in the 33 months before implementation to 82 a month per 100000 population in the 51 months after, was significantly less than the increase in the comparison cities, in which woundings recorded by the police increased from 54 to 114 a month per 100000 population. Rates of common assaults recorded by the police in Cardiff increased from 15 to 20 a month per 100000 population after implementation compared with a decrease from 42 to 33 a month per 100000 population in comparison cities.

\section{DISCUSSION}

Introduction of the Cardiff Violence Prevention Programme - an anonymised information sharing programme to prevent injury related to violence-was associated with a substantial and significant reduction in hospital admissions related to violence. Although violence is increasingly recognised as a public health problem, community level prevention is often limited to enforcement strategies to arrest and incarcerate perpetrators. The programme represents a novel approach to using relevant available data and expertise from health and law enforcement professionals working together in the context of a statutory, local government level partnership to develop violence prevention strategies. The partnership had significant and sustained effects on total assaults and assaults causing wounding recorded by the police as well as hospital admissions after violence. These findings show the potential benefits of data driven violence prevention partnerships in the community.

The graphs of rates of violence suggest that, after a period of about two years in which rates in the intervention city and comparison cities diverged, steady state was reached and differential rates were maintained thereafter. This suggests that effectiveness increased as the partners learned how to process data efficiently and to deliver prevention based on the combined data and that this learning became embedded in practice. 
Table $4 \mid$ Adjusted* incidence rate ratios $(95 \%$ confidence intervals) for specific years after implementation of Cardiff Violence Prevention Programme from negative binomial fixed effects regression models for total, common, and wounding assaults with interaction terms $\dagger$

\begin{tabular}{|cccc} 
& Total assaults & Common assaults & $\begin{array}{c}\text { Wounding } \\
\text { assaults }\end{array}$ \\
\hline 2003 & $0.93(0.84$ to 1.02$)$ & $1.92(1.43$ to 2.58$)$ & $0.83(0.72$ to 0.95$)$ \\
\hline 2004 & $0.71 \ddagger(0.64$ to 0.79$)$ & $1.16 \ddagger(0.79$ to 1.52$)$ & $0.64 \ddagger(0.54$ to 0.73$)$ \\
\hline 2005 & $0.77 \ddagger(0.69$ to 0.85$)$ & $1.29 \ddagger(0.90$ to 1.70$)$ & $0.66 \ddagger(0.57$ to 0.76$)$ \\
\hline 2006 & $0.81 \ddagger(0.73$ to 0.89$)$ & $1.44(1.03$ to 1.84$)$ & $0.66 \ddagger(0.57$ to 0.76$)$ \\
\hline 2007 & $0.72 \ddagger(0.59$ to 0.85$)$ & $1.51(0.78$ to 2.25$)$ & $0.58 \ddagger(0.42$ to 0.74$)$ \\
\hline
\end{tabular}

*Regression also controls for unemployment rate, police force level, implementation of national crime recording standard, calendar month, and year (results not shown).

†Interaction terms tested with 2003 as reference.

łnteraction significantly different from 2003 rate ratio at $\mathrm{P}<0.05$.

The cumulative nature of the strategies implemented by the partnership precludes an assessment of the unique effects of specific strategies. Trends in violence and temporal sequencing of the strategies, however, provide some insights. For example, while rates of woundings recorded by the police fell significantly after implementation of the programme, there was a concurrent increase in common assaults recorded by the police (that is, those not resulting in injuries). One plausible explanation for these findings is that more accurate targeting of hot spots, earlier and more frequent police ascertainment, and better deployment of public space CCTV led to faster and more frequent police intervention in assaults and their precursors (such as arguments). The increased presence of police at hot spots could also have led to increased reporting of common assaults by witnesses and victims and subsequent recording by police. These explanations are consistent with the findings of a controlled study of the effects of public space CCTV; installation was associated with increased police ascertainment of violence but decreased attendances at an emergency department after violence. ${ }^{39}$ More widely, this explanation is also consistent with the hypothesis that police intervention in the early stages of an assault can limit the severity of injury. ${ }^{40}$ An alternative explanation could be the greater use of plastic barware. Licensing conditions mandating the use of plastic barware in some city centre licensed premises, however, were introduced after the period in which violence in Cardiff and comparison cities diverged (that is, 2005, see fig 1) and the

\begin{tabular}{|c|c|c|c|}
\hline & $\begin{array}{l}\text { Cardiff } \\
(\mathrm{n}=72)\end{array}$ & $\begin{array}{l}\text { Comparison cities } \\
\qquad(n=276)\end{array}$ & $\begin{array}{l}\text { All cities } \\
(n=348)\end{array}$ \\
\hline Monthly hospital admissions from assault & $19(0.9)$ & $28(1.8)$ & $26(1.4)$ \\
\hline Monthly admissions rate/100 000 & $6(0.3)$ & $6(0.2)$ & $6(0.2)$ \\
\hline Population (thousands) & $312(0.4)$ & $398(13.8)$ & $380(11.1)$ \\
\hline Unemployment rate (\%) & $3(0.04)$ & $3(0.04)$ & $3(0.03)$ \\
\hline No of police/100 000 population & $467(2.7)$ & $394(3.1)$ & $409(2.9)$ \\
\hline
\end{tabular}
Figures are means (SE) number of glass related assaults was far too low to account for the observed reductions, indicating that the glassware change does not explain the divergence. Overall, however, it is striking that the divergence in violence rates in Cardiff and comparison cities is closely associated with the implementation of the mature data sharing process and the formal adoption by the city partners of the violence prevention programme, which had been, hitherto, in a development phase.

\section{Study limitations and strengths}

Limitations of the study should be considered when drawing implications for other communities. Firstly, the extent to which the decline in assaults, relative to other cities, can be attributed to the activities of the partnership is difficult to isolate. While no other major violence prevention activities occurred in Cardiff, it remains conceivable that other unmeasured factors contributed to the effects observed. The preventive effects, however, were observed after we controlled for several important potential explanatory factors, including changes in the national crime recording standard, police service strength, and unemployment rates. Also, it is possible that other novel prevention strategies were implemented during the study period in the comparison cities. Therefore, the effects observed are potentially weaker than they would have been if the comparison had been restricted to cities not implementing any new prevention strategies. Secondly, it is difficult to assess whether the declines in violence can be attributed to potential victims avoiding the areas being targeted. For example, an alternative explanation for the decrease in assaults could be that people visiting city centres at night learn to avoid locations that are receiving increased police attention and move elsewhere. The lower levels of hospital admissions related to violence, however, show that even if some displacement of violence did occur, there was still an overall reduction in serious injuries. Hospital data, in contrast with police data, are not, of course, affected by attitudes to police involvement. $^{21}$ Thirdly, the generalisability of the results to specific types of violence is unclear. For example, victims of domestic violence might not report violence as the cause of their injury to reception staff in an emergency department and therefore domestic violence might not have driven prevention strategies in proportion to the extent of this problem. Furthermore, it is possible that cultural and political differences in the nature of violence within communities affect the utility of this approach. There may be barriers to successful community partnerships that other communities will need to overcome to see similar benefits. These barriers could include lack of analytical capacity, fears about breaches of confidentiality (unjustifiable given the non-personal nature of the data), ${ }^{41}$ lack of a science based culture in the police service, and the lack of a prevention focus in emergency services. The prevention enterprise described here depends on sustained and continuous capture, sharing, and use of data; absence or disruption of any of these 
Table 6 | Adjusted* incidence rate ratios $(95 \%$ confidence interval) from negative binomial fixed effects regression model for hospital admissions because of assault after implementation of Cardiff Violence Prevention Programme

Incidence rate ratio $(95 \% \mathrm{Cl})$

\begin{tabular}{ll} 
Programme implemented & $0.58(0.49$ to 0.69$)$ \\
\hline Unemployment rate & $0.79(0.67$ to 0.94$)$ \\
\hline Police/100 000 population & $1.00(1.00$ to 1.01$)$
\end{tabular}

*Regression also controls for calendar month and year (results not shown).

steps is likely to reduce effectiveness. With the necessary resources and support, however, this is likely to be a viable approach for communities.

\section{Conclusions and policy implications}

We concluded that the Cardiff Violence Prevention Programme is associated with a substantial and sustained reduction in violence related harm, whether recorded by health services or by the police. This effect was observed only for violence causing wounding and not for more minor violence; the intervention was associated with an estimated $42 \%$ fewer woundings recorded by the police relative to comparison cities four years after implementation. While other evaluations of violence prevention strategies often focus on changes in behaviour (such as student reports of fighting) or impacts within a narrow target population, the outcomes reported here reflect community level changes in injury sustained in violence.

This data sharing model is currently being implemented in the UK (there is a coalition government commitment to information sharing by hospitals in England for violence prevention) and is advocated by WHO. ${ }^{15}$ As a public health strategy the model is intended to be dynamic, interdisciplinary, and comprehensive (that is, not dealing only with particular categories of violence such as gang violence). Communities could use this partnership approach to identify gaps in local prevention strategies and to introduce appropriate programmes and policies based on the best available evidence. For example, interventions

\section{WHAT IS ALREADY KNOWN ON THIS TOPIC}

A substantial proportion of violence that results in treatment by doctors is not known to the police

Though targeted police work prevents violence, targeting depends on knowledge of when and precisely where violence occurs

It is not known whether the use of information about the location and times of injury derived from patients injured in violence can improve violence prevention

\section{WHAT THIS STUDY ADDS}

Anonymised information derived from patients injured in violence can, when combined with police intelligence, be used to prevent violence to a greater extent than is achievable using police intelligence alone

The principal implication for policy, practice, and public health is that organised continuous sharing and use of anonymised data about violence and the involvement of clinicians in partnership work are important contributions to achieving safer communities to improve the social cognitive skills of youth and family based programmes to enhance parental monitoring of youth, as well as community level programmes such as Ceasefire's efforts to diffuse escalating community violence ${ }^{42-44}$ and boys and girls clubs' work to provide stable adult mentors ${ }^{45}$ could be introduced on this basis.

Our findings suggest that communities can achieve substantial reductions in the public health burden of violence through organised data driven partnerships between health, law enforcement agencies, and local government. Furthermore, as police ascertainment of violence that results in injury is limited in all countries where data matching studies and national crime surveys have been carried out, ${ }^{13}$ and, reflecting comparatively little investment in law enforcement, it is likely to be even lower in low and middle income countries, it seems likely that the main conclusions of this study are generalisable outside the UK.

We thank Robert Newcombe (professor of medical statistics, Cardiff University), Fred Rivara (professor of epidemiology, Harborview Injury Prevention and Research Centre, University of Washington), and Linda Dahlberg (Centers for Disease Control) for helpful comments on an earlier draft of this article. We also thank Paul Taylor at the Home Office for collation of recorded crime data. The findings and conclusions in this report are those of the authors and do not necessarily represent the official position of the Centers for Disease Control and Prevention. Contributors: CF, JS, IB, and TS designed the analyses and wrote the manuscript. CF conducted the statistical analyses. IB collated the data and conducted the data review. JS conceived the hypothesis and initiated the programme, data sharing arrangements, and the prototype community partnership (which he convened and chaired throughout the period of the study). All authors saw and approved the final version of the manuscript. JS is guarantor.

Funding: The development of the prototype partnership was funded in part by a grant from the Home Office targeted policing fund. The study was funded in part by the Wales Office for Research and Development in Health and Social Care (WORD), grant No R/98/037.

Competing interests: All authors have completed the ICMJE uniform disclosure form at www.icmje.org/coi_disclosure.pdf (available on request from the corresponding author) and declare: no support from any organisation for the submitted work; no financial relationships with any organisations that might have an interest in the submitted work in the previous three years; no other relationships or activities that could appea to have influenced the submitted work.

Ethical approval: Not required.

Data sharing: No additional data available.

1 World Health Organization. The global burden of disease, 2004 update. WHO, 2008.

2 Walker A, Flatley J, Kershaw C, Moon D. Crime in England and Wales, 2008/09: findings from the British Crime Survey and police recorded crime. Home Office, 2009.

3 Dubourg R. The economic and social costs of crime against individuals and households 2003/04. Home Office, 2005.

4 World Health Organization. World report on violence and health. WHO, 2002.

5 Dahlberg LL, Butchart A. State of the science: violence prevention efforts in developing and developed countries. Int J Contr Saf Promot 2005;12:93-104.

6 Shepherd JP, Ali MA, Hughes AO, Levers BGH. Trends in urban violence: a comparison of accident department and police records. J $R$ Soc Med 1993;86:87-9.

7 Sutherland I, Sivarajasingam V, Shepherd JP. Recording of community violence by medical and police services. Inj Prev 2002;8:246-7.

8 Faergemann C, Lauritsen JM, Brink O, Skov O. Trends in deliberate interpersonal violence in the Odense Municipality, Denmark 1991. 2002: the Odense study on deliberate interpersonal violence. J Forensic Leg Med 2007;14:20-6.

9 Kellermann AL, Bartolomeos K, Fuqua-Whitely D, Sampson TR, Parramore CS. Community-level firearm injury surveillance: local data for local action. Ann Emerg Med 2001;38:423-9. 
10 Clarkson C, Cretney A, Davis G, Shepherd JP. Assaults: the relationship between seriousness, criminalisation and punishment. Crim Law Rev 1994;4:4-20.

11 Sachs CJ, Peek C, Baraff LJ, Hasselbad V. Failure of the mandatory domestic violence reporting law to increase medical facility referral to police. Ann Emerg Med 1998;31:488-94.

12 Houry D, Sachs J, Feldhaus KM, Linden J. Violence inflicted injuries: reporting laws in the fifty states. Ann Emerg Med 2002;39:56-60.

13 Farrington D, Langan PA, Tonry M. Cross-national studies in crime and justice. US Bureau of Justice Statistics, 2004.

14 Villaveces A, Cummings P, Espitia VE, Koepsell TD, McKnight B, Kellermann AL. Effect of a ban on carrying firearms on homicide rates in 2 Colombian cities. JAMA 2000;283:1205-9.

15 World Health Organization. Preventing violence: a guide to implementing the recommendations of the World report on violence and health. WHO, 2004.

16 Mercy JA, Barker L, Frazier L. The secrets of the national violent death recording system. Inj Prev 2006;12 (suppl 2):ii1-12.

17 Weisburd D, Green L. Policing drug hot spots: the Jersey city drug market analysis experiment. Justice Q 1995;12:711-36.

18 Sherman LW, Weisburd D. General deterrent effects of police patrol in crime "hot spots": a randomised, controlled trial. Justice $Q$ 1995;12:625-48.

19 Braga AA. The effects of hot spots policing on crime. Campbell Systematic Reviews 2007;1-36.

20 Clarke RV, Weisburd D. Diffusion of crime control benefits: observations on the reverse of displacement. In: Clarke RV, ed. Crime prevention studies. Willow Tree Press, 1994:165-83.

21 Shepherd J. Emergency medicine and police collaboration to prevent community violence. Emerg Med J 2001;38:430-37.

22 Warburton AL, Shepherd JP. Development, utilisation, and importance of accident and emergency department derived assault data in violence management. Emerg Med / 2004;21:473-7.

23 Warburton AL, Shepherd JP. Tackling alcohol related violence in city centres: effect of emergency medicine and police intervention. Emerg Med / 2006;23:12-7.

24 Goodwin V, Shepherd JP. The development of an assault patient questionnaire to allow accident and emergency departments to contribute to Crime and Disorder Act local crime audits. Emerg Med 2000;17:196-8.

25 Crown Prosecution Service. Offences against the person, incorporating the charging standard. www.cps.gov.uk/legal/L_to_o/ offences against the person/.

26 Shepherd JP, Shapland M, Pearce NX, Scully C. Pattern, severity and aetiology of injuries in victims of assault. J R Soc Med 1990;83:75-8.

27 Harper G, Williamson I, Clarke G, See L. Family origins: developing groups of Crime and Disorder Reduction Partnerships and police Basic Command Units for comparative purposes. Home Office, 2002.
28 Giacopassi D, Forde DR. Broken windows, crumpled fenders, and crime. J Criminal Justice 2000;28:397-405.

29 Shepherd JP, Robinson BG, Levers BGH. Roots of urban crime. Injury 1986;21:139-41.

30 Sisson D, Nguyen KT. Police service strength England and Wales. Home Office, 2001.

31 Povey D, Nguyen KT. Police service strength England and Wales, 31 March 2001. Home Office, 2001.

32 Smith C, Rundle S, Hosking R. Police service strength England and Wales, 31 March 2002. Home Office, 2002.

33 Cotton J, Smith C. Police service strength England and Wales, 31 March 2003. Home Office, 2003.

34 Christopherson 0, Cotton J. Police service strength England and Wales, 31 March 2004. Home Office, 2004.

35 Bibi N, Clegg M, Pinto R. Police service strength England and Wales, 31 March 2005. Home Office, 2005.

36 Clegg M, Kirwan S. Police service strength England and Wales, 31 March 2006. Home Office, 2006.

37 Bullock S, Gunning N. Police service strength England and Wales, 31 March 2007. 2nd ed. Home Office, 2007.

38 Simmons J, Legg C, Hosking G. National Crime Recording Standard (NCRS): an analysis of the impact on recorded crime. Home Office, 2003.

39 Sivarajasingam V, Corcoran J, Jones D, Ware A, Shepherd JP. Relations between violence, calendar events and ambient conditions. Injury 2004;35:467-73.

40 Sivarajasingam V, Shepherd JP, Matthews K. Effect of urban closed circuit television on assault injury and violence prevention. Inj Prev 2003;9:312-6.

41 Shepherd J. Criminal deterrence as a public health strategy. Lancet 2001;358:1717-22.

42 Ritter N. CeaseFire: a public health approach to reduce shootings and killings. National Institute Justice J 2009;264:20-5.

43 Center for the Study and Prevention of Violence. Blueprints for violence prevention. www.colorado.edu/cspv/blueprints/.

44 Hahn H, Fuqua-Whitley D, Wethington H, Lowy J, Liberman A, Crosby A, et al and Centers for Disease Control. The effectiveness of universal school-based programs for the prevention of violent and aggressive behavior: a report on recommendations of the task force on community preventive sevices. MMWR Recomm Rep 2007;56:1-12.

45 St Pierre TL, Kaltreider DL, Mark MM, Aikin KJ. Drug prevention in a community setting: a longitudinal study of the relative effectiveness of a three-year primary prevention programme in boys and girls clubs across the nation. Am J Commun Psychol 1992;20:673-706.

Accepted: 15 April 2011 